\title{
Successful Salvage Treatment of Resistant Acute Antibody-Mediated Kidney Transplant Rejection with Eculizumab
}

"Saif A. Khan, ${ }^{1}$ Dawood Al-Riyami, ${ }^{1}$ Yasser W. Al-Mula Abed, ${ }^{1}$ Saja Mohammed, ${ }^{1}$ Marwa Al-Riyami, ${ }^{2}$ Nabil M. Al-Lawati ${ }^{3}$

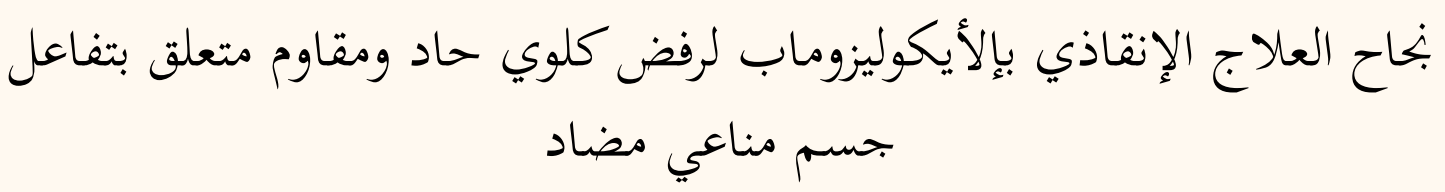

سيف خان، داوود الريامي، ياسر الملاعبد، سجى محمد، مروة الريامي، نبيل اللواتيا

ABSTRACT: Antibody-mediated rejection (ABMR) jeopardises short- and long-term transplant survival and remains a challenge in the field of organ transplantation. We report the first use of the anticomplement agent eculizumab in Oman in the treatment of a 61-year-old female patient with ABMR following a living unrelated kidney transplant. The patient was admitted to the Sultan Qaboos University Hospital in Muscat, Oman, in 2013 on the eighth day post-transplantation with serum creatinine $(\mathrm{Cr})$ levels of $400 \mu \mathrm{mol} / \mathrm{L}$ which continued to rise, necessitating haemodialysis. A biopsy indicated ABMR with acute cellular rejection. No improvement was observed following standard ABMR treatment and she continued to require dialysis. Five doses of eculizumab were administered over six weeks with a subsequent dramatic improvement in renal function. The patient became dialysis-free with serum $\mathrm{Cr}$ levels of $119 \mu \mathrm{mol} / \mathrm{L}$ within four months. This case report indicates that eculizumab is a promising agent in the treatment of ABMR.

Keywords: Kidney Transplantation; Transplantation Rejection; Complement Activation; Eculizumab; Case Report; Oman.

الملخص: يهدد رفض زرع الكلى الحاد بواسطة الجسم المضاد بقاء الزرعه لفترات قصيرة وطويلة الأجل ويبقى من التحديات في مجال

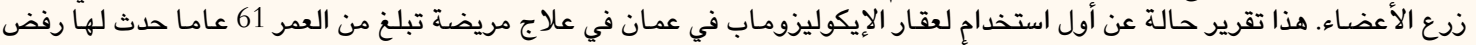

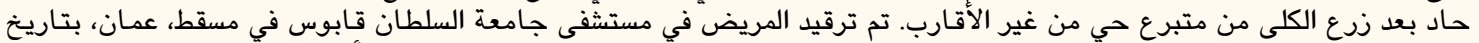

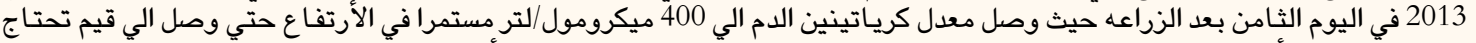

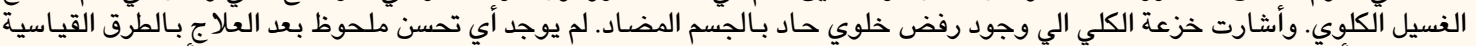

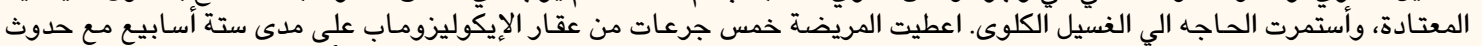

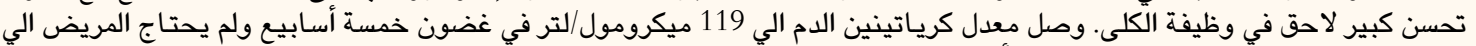

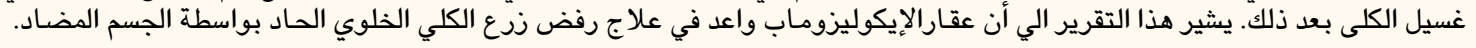

$$
\text { كلمات مفتاحية؛ زراعة الكلى؛ رفض الزرعه؛ تنشيط الكومبليمنت؛ عقار الإيكوليزوماب؛ تقريرحالة؛ عُمان. }
$$

$\mathrm{M}$ ANy ADVANCES HAVE BeEN MADE IN the last 50 years in the field of kidney transplantation due to improved understanding of the role of the immune system in allograft rejection. Additionally, the introduction of powerful immunosuppressive agents like calcineurin inhibitors has significantly reduced acute cellular rejection rates and substantially improved oneyear transplant survival rates. ${ }^{1}$ Despite this, organ rejection is still a major obstacle and long-term posttransplantation outcomes ( $\geq 10$ years) have not shown much improvement. ${ }^{2}$

Hyper acute rejection caused by preformed donorspecific antibodies (DSAs) is now extremely rare due to the universal implementation of pre-transplant cross- matching. Antibody-mediated rejection (ABMR) has proven to play a critical role in the short- and longterm survival of kidney allografts. When untreated or insufficiently treated, ABMR may lead to chronic changes that ultimately result in graft loss. ${ }^{3}$ This case report demonstrates the successful recovery of renal function due to the administration of eculizumab in a patient with ABMR following a living unrelated transplant.

\section{Case Report}

A 61-year-old Omani woman with end-stage renal disease due to hypertension was admitted to the Sultan Qaboos University Hospital in 2013 eight days post- 

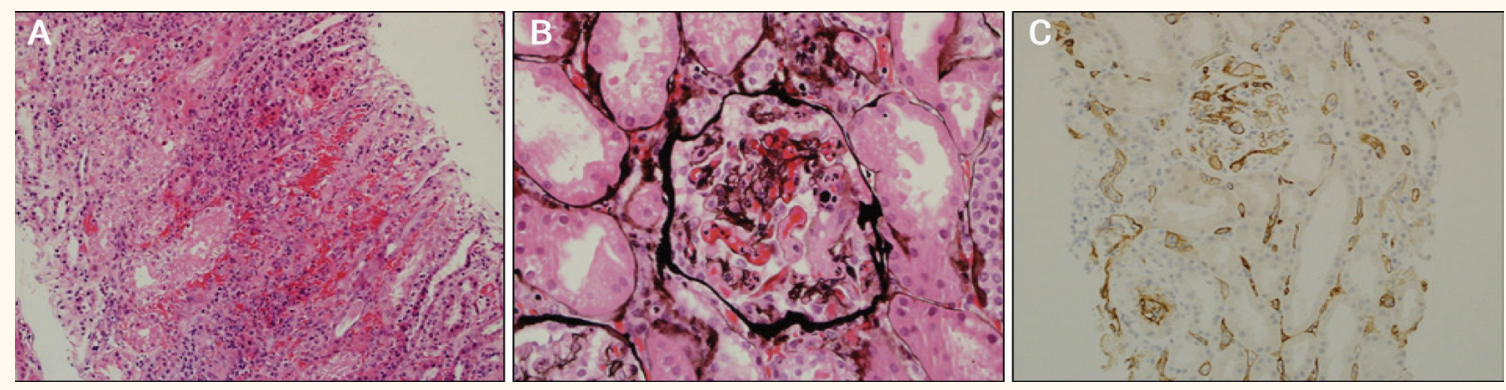

Figure 1A-C: A: Haematoxylin and eosin stain at x200 magnification showing an area of interstitial haemorrhage with acute inflammation. B: Jones' stain at x400 magnification showing glomerular thrombosis with intraluminal neutrophils. C: Complement component $4 \mathrm{~d}$ stain at x200 magnification showing strong diffuse positive staining.

transplantation. She had no history of spontaneous abortions or venous thromboem-bolisms. She had been on regular haemodialysis at a local dialysis centre for three years before undergoing a living unrelated kidney transplant abroad. Unfor-tunately, details regarding tissue typing, cross-matching, immune suppression induction and the operative procedure were unavailable. At presentation, she had serum creatinine levels of $>400 \mu \mathrm{mol} / \mathrm{L}$ which increased to $607 \mu \mathrm{mol} / \mathrm{L}$ a few days later.

Ultrasonography of the transplanted kidney showed a normal-sized graft with a resistive index of 0.91 . Four days after admission, on the $12^{\text {th }}$ postoperative day, an ultrasound-guided renal transplant biopsy showed glomerular thrombosis, mild peritubular capillaritis, interstitial haemorrhage, strong complement component 4 (C4) d positivity in the peritubular capillaries, mild to moderate focal lymphocytic tubulitis and mild interstitial inflammation [Figure 1]. The arteries and arterioles were normal. These findings were consistent with acute class II ABMR and T cell-mediated acute cellular rejection (ACR). The patient was treated with $250 \mathrm{mg}$ of intravenous methylprednisolone for three days, $1.5 \mathrm{mg} / \mathrm{kg}$ of rabbit anti-thymocyte globulin for a total cumulative dose of $980 \mathrm{mg}, 2 \mathrm{~g} / \mathrm{kg}$ of intravenous immunoglobulin (IVIG) and five cycles of plasma exchange (PLEX) at $2.5 \mathrm{~L}$ per exchange. She also received maintenance immunosuppression with oral prednisolone, tacrolimus and mycophenolate.

The patient showed no improvement in renal function and remained dialysis-dependent after four weeks of conventional treatment. A second biopsy was performed on the $32^{\text {nd }}$ day post-transplantation which indicated on-going ABMR (acute thrombotic microangiopathy, peritubular capillaritis and strong C4d positivity) and features of chronic ABMR, but no evidence of significant ACR. Intimal fibrosis was seen in the arteries as the result of an earlier acute rejection. These findings were believed to indicate resistance to conventional treatment; as a result, the decision was made to proceed with eculizumab administration. Other treatment options such as rituximab and bortezomib were not considered in view of the strong C4d staining in the peritubular capillaries and persistent findings of ABMR indicative of complement pathway activation. The patient received a meningococcal vaccine two weeks prior to the initiation of the eculizumab treatment as per the manufacturers' recommendations. She received a total of five doses of eculizumab, with the first four doses of $900 \mathrm{mg}$ administered on a weekly basis and the fifth dose of $1,200 \mathrm{mg}$ given two weeks after the fourth dose. A dramatic response in renal function was observed following the first dose [Figure 2]. Her serum creatinine levels continued to improve and had decreased to $119 \mu \mathrm{mol} / \mathrm{L}$ four months after the eculizumab treatment.

\section{Discussion}

ABMR occurs in $5-7 \%$ of all renal transplants and $20-48 \%$ of pre-sensitised positively cross-matched patients. ${ }^{4}$ Graft dysfunction usually manifests within a few days of the transplant procedure; however, allograft dysfunction with a resultant increase in serum creatinine may not be present in all cases. ${ }^{4}$ DSAs play a major role in transplant rejection;

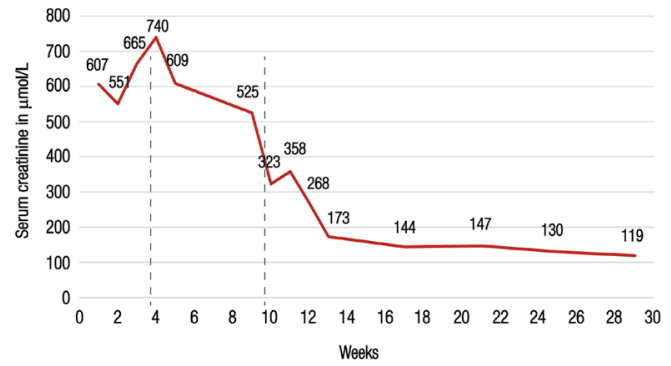

Figure 2: Serum creatinine levels in a 61-year-old Omani woman with antibody-mediated rejection following a kidney transplant. The patient showed no improvement after six weeks of conventional therapy and was treated with five doses of eculizumab; she became dialysis-free after the first dose. The dotted lines represent the timing of the first and final doses of eculizumab, respectively. 
they are either preformed or develop de novo after transplantation. ${ }^{5}$ These antibodies are most commonly directed against the human leukocyte antigen (HLA) or major histocompatibility complex (MHC) class I and II. The former is expressed in all nucleated cells while the latter is restricted to endothelial cells and antigen-presenting cells like dendritic cells and B-lymphocytes. The antibodies can also be directed against other DSAs/non-HLA-like platelets, specific antigens, renin-angiotensin pathways and MHC class I-related chain A. Previous transplantations, pregnancy and blood transfusions are major risk factors leading to sensitisation against MHC. ${ }^{6}$ Anti-MHC antibodies either result in direct injury to the capillary endothelium or indirect injury via complement activation which is the major mechanism leading to the formation of a membrane attack complex. This formation results in cell injury and manifests histologically as glomerulitis, peritubular capillaritis and vascular endothelial injury. Endothelial damage also causes platelet activation and microthrombus formation.

The Banff Foundation for Allograft Pathology has proposed that at least two of the following criteria indicate a diagnosis of ABMR: (1) the presence of DSAs; (2) a positive C4d stain; and (3) histological evidence of glomerulitis, peritubular capillaritis and vascular endothelial injury. ${ }^{7,8}$ In the present case, two of the above criteria were met. However, the patient was not tested for panel-reactive antibodies or DSAs; the latter was due to the unavailability of the technique at that time in Oman. However, it is an established practice to initiate treatment of ABMR in circumstances where the criteria are not entirely fulfilled due to multiple factors, including an inability to measure DSAs due to the presence of non-HLA antibodies or the possibility of DSA adsorption into the allograft. ${ }^{9}$ On the other hand, C4d stains may be falsely negative in areas of necrosis or with less sensitive immunohistochemistry techniques. Protocol biopsies have also demonstrated C4d variability in staining over time from positive to negative. ${ }^{8}$

The complement split product $\mathrm{C} 4 \mathrm{~d}$ results from the breakdown of $\mathrm{C} 4 \mathrm{~b}$ into $\mathrm{C} 4 \mathrm{~d}$ and $\mathrm{C} 4 \mathrm{c}$. It has a high affinity for endothelial and basement membranes and is expressed in the normal kidney mesangium and vascular pool owing to the constant complement turnover. ${ }^{10}$ In cases of immune-mediated glomerulopathy, it extends into the glomerular capillaries and deposits in the peritubular capillaries in a transplanted kidney. Immunohistochemistry and immunofluorescence are two methods to detect C4d, the latter of which is more sensitive. Diffuse staining of $\mathrm{C} 4 \mathrm{~d}$ (more than $50 \%$ of a peritubular capillary stain) is highly suggestive of $A B M R$, in comparison to focal
(10-50\%) and minimal (<10\%) staining. ${ }^{8}$

The goal of ABMR treatment is the reduction and removal of DSAs and the elimination of the B cell and plasma cell population responsible for the production of these antibodies. The international guidelines do not outline any evidence-based treatments for acute ABMR. ${ }^{11}$ Historically, IVIG and PLEX therapy have been used as first-line treatments for ABMR. ${ }^{11}$ These therapies are difficult to assess because treatment options, doses and regimens are not standardised. Moreover, no randomised control studies have supported the use of IVIG in acute ABMR despite its common utilisation in this context. ${ }^{12}$ Although the role of PLEX has not been confirmed, studies have shown it to be beneficial especially in combination with other agents. ${ }^{13,14}$ Other strategies for managing ABMR include the use of rituximab, which targets pre- $B$ cells and $\mathrm{B}$ cells, and bortezomib, which is a proteasome inhibitor. ${ }^{15,16}$ Uncontrolled randomised studies have shown benefit in both rituximab and bortezomib. ${ }^{11,17}$ These agents are usually used in conjunction with IVIG and/or PLEX. ${ }^{11}$

Eculizumab is a humanised monoclonal antibody directed against complement protein- $\mathrm{C}$ and has recently been used as a new therapeutic agent for ABMR with emerging data supporting its applicability and efficacy in kidney transplantation. ${ }^{11,18}$ It is a terminal complement inhibitor initially approved for the management of paroxysmal nocturnal haemoglobinuria and atypical haemolytic uremic syndrome. ${ }^{19,20}$ It targets complement component 5, thus blocking the complement cascade and the formation of the complement membrane attack complex. ${ }^{21}$ To the best of the authors' knowledge, the present case report is the first to detail the use of eculizumab to treat ABMR in Oman. In this case, eculizumab was administered after a failed response to conventional treatment (IVIG, PLEX, steroids and anti-thymocyte globulin) and histological evidence of persistent ABMR on a repeated graft biopsy four weeks post-transplantation. The patient exhibited a dramatic improvement in renal function following five doses of eculizumab. González-Roncero et al. confirmed the efficacy of this agent in the treatment of two cases of ABMR, especially when the biopsy shows C4d staining. ${ }^{22}$ Several other reports also endorse the use of eculizumab in the treatment of ABMR. ${ }^{23,24}$ However, these findings need to be confirmed by randomised control trials. The current case report highlights a common dilemma arising from commercial transplants, particularly as these surgeries may be carried out without optimal preparation and with limited peri-operative information available following the procedure. 


\section{Conclusion}

ABMR is a serious complication that can occur following organ transplantation. It can have a grave impact on long-term kidney transplant survival. Several non-evidence-based strategies exist to treat ABMR. This case report presents the first use of eculizumab in Oman to treat ABMR. The successful outcome of this case indicates that eculizumab may be a promising agent in the treatment of this condition. However, randomised control trials are needed to confirm the efficacy of this agent.

\section{References}

1. Watson CJ, Dark JH. Organ transplantation: Historical perspective and current practice. Br J Anaesth 2012; 108:i29-42. doi: $10.1093 / \mathrm{bja} /$ aer384.

2. Coll E, Crespo M, Solé M, Campistol JM, Cofàn F, Esforzado N, et al. Lessons from cyclosporine monotherapy in renal transplantation: The impact of acute rejection on longterm allograft outcome. Transplant Proc 2004; 36:114S-6S. doi: 10.1016/j.transproceed.2004.01.116

3. Amore A. Antibody-mediated rejection. Curr Opin Organ Transplant 2015; 20:536-42. doi: 10.1097/MOT.00000000000 00230.

4. Puttarajappa C, Shapiro R, Tan HP. Antibody-mediated rejection in kidney transplantation: A review. J Transplant 2012; 2012:193724. doi: 10.1155/2012/193724.

5. Stastny P, Zou Y, Fan Y, Qin Z, Lavingia B. The emerging issue of MICA antibodies: Antibodies to MICA and other antigens of endothelial cells. Contrib Nephrol 2009; 162:99-106. doi: $10.1159 / 000170842$.

6. Picascia A, Grimaldi V, Sabia C, Napoli C. Comprehensive assessment of sensitizing events and anti-HLA antibody development in women awaiting kidney transplantation. Transpl Immunol 2016; 36:14-19. doi: 10.1016/j.trim.2016.03.002.

7. Solez K, Racusen LC. The Banff classification revisited. Kidney Int 2013; 83:201-6. doi: 10.1038/ki.2012.395.

8. Haas M. The revised (2013) Banff classification for antibodymediated rejection of renal allografts: Update, difficulties, and future considerations. Am J Transplant 2015; 16:1352-7. doi: $10.1111 /$ ajt.13661

9. Burton SA, Amir N, Asbury A, Lange A, Hardinger KL. Treatment of antibody-mediated rejection in renal transplant patients: A clinical practice survey. Clin Transplant 2015; 29:118-23. doi: 10.1111/ctr.12491.

10. Feucht HE. Complement C4d in graft capillaries: The missing link in the recognition of humoral alloreactivity. Am J Transplant 2003; 3:646-52. doi: 10.1034/j.1600-6143.2003.00171.x.

11. Yilmaz VT, Suleymanlar G, Koksoy S, Ulger BV, Ozdem S, Akbas $\mathrm{H}$, et al. Therapy modalities for antibody mediated rejection in renal transplant patients. J Invest Surg 2016; 1-7 [Epub ahead of print]. doi: 10.3109/08941939.2016.1154626.
12. Archdeacon P, Chan M, Neuland C, Velidedeoglu E, Meyer J, Tracy L, et al. Summary of FDA antibody-mediated rejection workshop. Am J Transplant 2011; 11:896-906. doi: 10.1111/j.1600-6143.2011.03525.x.

13. Rocha PN, Butterly DW, Greenberg A, Reddan DN, Tuttle-Newhall J, Collins BH, et al. Beneficial effect of plasmapheresis and intravenous immunoglobulin on renal allograft survival of patients with acute humoral rejection. Transplantation 2003; 75:1490-5.

14. Al-Badr W, Kallogjeri D, Madaraty K, Oliver D, Bastani B, Grossman BJ. A retrospective review of the outcome of plasma exchange and aggressive medical therapy in antibody mediated rejection of renal allografts: A single center experience. J Clin Apher 2008; 23:178-82. doi: 10.1002/jca.20181.

15. Kaposztas Z, Podder H, Mauiyyedi S, Illoh O, Kerman R, Reyes $M$, et al. Impact of rituximab therapy for treatment of acute humoral rejection. Clin Transplant 2009; 23:63-73. doi: 10.1111/j.1399-0012.2008.00902.x

16. Flechner SM, Fatica R, Askar M, Stephany BR, Poggio E, Koo A, et al. The role of proteasome inhibition with bortezomib in the treatment of antibody-mediated rejection after kidney-only or kidney-combined organ transplantation. Transplantation 2010; 90:1486-92. doi: 10.1097/TP.0b013e3181fdd9b0.

17. Everly MJ, Everly JJ, Susskind B, Brailey P, Arend LJ, Alloway RR, et al. Bortezomib provides effective therapy for antibody- and cell-mediated acute rejection. Transplantation 2008; 86:175461. doi: 10.1097/TP.0b013e318190af83

18. Johnson CK, Leca N. Eculizumab use in kidney transplantation. Curr Opin Organ Transplant 2015; 20:643-51. doi: 10.1097/ MOT.0000000000000249.

19. Emadi A, Brodsky RA. Successful discontinuation of anticoagulation following eculizumab administration in paroxysmal nocturnal hemoglobinuria. Am J Hematol 2009; 84:699-701. doi: 10.1002/ajh.21506.

20. Nürnberger J, Philipp T, Witzke O, Opazo Saez A, Vester U, Baba HA, et al. Eculizumab for atypical hemolytic-uremic syndrome. N Engl J Med 2009; 360:542-4. doi: 10.1056/ NEJMc0808527.

21. Frémeaux-Bacchi $\mathrm{V}$, Legendre $\mathrm{CM}$. The emerging role of complement inhibitors in transplantation. Kidney Int 2015; 88:967-73. doi: $10.1038 / \mathrm{ki} .2015 .253$.

22. González-Roncero F, Suñer M, Bernal G, Cabello V, Toro M, Pereira P, et al. Eculizumab treatment of acute antibody-mediated rejection in renal transplantation: Case reports. Transplant Proc 2012; 44:2690-4. doi: 10.1016/j. transproceed.2012.09.038

23. Legendre C, Sberro-Soussan R, Zuber J, Rabant M, Loupy A, Timsit $\mathrm{MO}$, et al. Eculizumab in renal transplantation. Transplant Rev (Orlando) 2013; 27:90-2. doi: 10.1016/j. trre.2013.04.002.

24. Locke JE, Margo CM, Singer AL, Segev DL, Haas M, Hillel AT, et al. The use of antibody to complement protein C5 for salvage treatment of severe antibody-mediated rejection. Am J Transplant 2009; 9:231-5. doi: 10.1111/j.16006143.2008.02451.x 